\title{
Influence of Inoculum Density, Wetness Duration, Plant Age, Inoculation Method, and Cultivar Resistance on Infection of Pepper Plants by Colletotrichum coccodes
}

\author{
Jeum Kyu Hong, Graduate Student, and Byung Kook Hwang, Professor, Department of Agricultural Biology, \\ Korea University, Seoul 136-701
}

\begin{abstract}
Hong, J. K., and Hwang, B. K. 1998. Influence of inoculum density, wetness duration, plant age, inoculation method, and cultivar resistance on infection of pepper plants by Colletotrichum coccodes. Plant Dis. 82:1079-1083.

Effects of inoculum density, wetness duration, plant age, inoculation method, and cultivar resistance on the development of pepper anthracnose caused by Colletotrichum coccodes were evaluated under controlled environmental conditions. As inoculum density of $C$. coccodes increased from $10^{3}$ to $10^{6}$ conidia/ml, symptoms of anthracnose developed. Disease severity also increased with increasing time of wetness duration from 0 to $60 \mathrm{~h}$. Wetness duration above $48 \mathrm{~h}$ and a high inoculum density at $10^{6}$ conidia/ml caused severe defoliation and blight symptoms in pepper seedlings. Inoculum at $10^{4}$ conidia/ml and 24 to $36 \mathrm{~h}$ of continuous wetness duration was enough to form irregular or circular brown lesions on pepper leaves. Age-related resistance was expressed as pepper plants matured. To evaluate resistance, the foliar-inoculation method was more reliable than the soil-drench method, which did not induce symptoms on older plants. The responses of 35 pepper cultivars or accessions tested to $C$. coccodes were quantitative rather than qualitative. No hypersensitive symptoms were observed in any of the cultivars inoculated with any of the two isolates. No significant differences in susceptibility to anthracnose were found among cultivars from Korea, the United States, India, and Thailand or accessions tested, irrespective of genetic or country origin of cultivars. The Korean cultivar Kwangbok was relatively less susceptible to anthracnose, compared with the other cultivars tested.
\end{abstract}

Anthracnose of pepper (Capsicum annuum L.) is one of the most destructive diseases in pepper-growing areas of Korea (21). The disease produces symptoms on leaves, stems, and fruits. Decay of mature red fruit caused by anthracnose can result in substantial reductions in pepper yield. Recently, Park and Kim (21) reported that five anthracnose fungi, Colletotrichum gloeosporioides, C. dematium, C. coccodes, C. acutatum, and Glomerella cingulata, are pathogenic to different tissues of pepper plants. Of these anthracnose fungi, C. gloeosporioides attacks the fruit at all stages of development, but not the leaves and stems of pepper plants $(13,21)$.

Leaf anthracnose of pepper seedlings caused by $C$. coccodes was first found in pepper-growing fields in Chungnam province of Korea in 1988 (19). In severely infested fields, a large number of pepper seedlings were defoliated and lodged. $C$.

Corresponding author: B. K. Hwang

E-mail: bkhwang@kuccnx.korea.ac.kr

This study was supported in part by funds from the Korea Science and Engineering Foundation.

Accepted for publication 8 June 1998.

Publication no. D-1998-0724-02R

(c) 1998 The American Phytopathological Society coccodes can infect pepper seeds, seedling leaves and stems, mature leaves, and sometimes green but not red fruits $(19,21,24)$. Initial symptoms of the anthracnose often appear on the leaves of pepper seedlings as light brown flecks. The flecks become slightly sunken, gradually increase in size, and coalesce to form larger, irregular lesions and blights on the leaves. $C$. coccodes has a wide host range that includes at least 58 species in 17 families, primarily in Leguminosae, Solanaceae, and Cucurbitaceae (22).

Extensive studies have been conducted to examine the effects of diverse environmental variables on infection and lesion development, yield losses, and the control of $C$. coccodes in tomato and potato $(1,5,7-10,15,16,20,23)$. The relationship, however, between environmental conditions and $C$. coccodes infection has not been established in pepper seedlings. Severe outbreaks of foliar and seedling anthracnose caused by $C$. coccodes in seedbeds under polyethylene (21) may be associated with a high relative humidity during the pepper-growing season. In general, pepper plants seem to acquire resistance to $C$. coccodes as they mature, since the anthracnose caused by $C$. coccodes does not readily occur in mature pepper plants (21). Differences in resistance to $C$. coccodes-infection have been demonstrated among cultivars of tomato, but the expression of resistance was greatly influenced by inoculation methods (4). Although effective control of anthracnose in pepper fields can be achieved by growing resistant cultivars, few pepper cultivars or accessions from diverse genetic origins have been evaluated for resistance to $C$. coccodes.

In this study, the effect of inoculum density, wetness duration, plant age, and inoculation method on infection of pepper seedlings by $C$. coccodes was evaluated. Levels of resistance of pepper genotypes from different genetic and geographic origins were also examined using two isolates of $C$. coccodes under greenhouse conditions.

\section{MATERIALS AND METHODS}

Inoculum and plant. Isolates 2-25, 32, and 7-48 of C. coccodes (Wallr.) S.J. Hughes obtained from the Plant Pathology Division of the National Agricultural Sciences and Technology Institute in Korea were used in this study. Mycelial suspensions from 7-day-old cultures were spread onto oatmeal agar plates. The cultures were grown at $28^{\circ} \mathrm{C}$ under continuous fluorescent light. After incubation for 5 to 7 days, inoculum was prepared by gently scraping the agar surface in sterile water, then filtering the mycelial and conidial suspension through four layers of cheesecloth. The conidial suspensions were counted using a hemacytometer and adjusted from $10^{3}$ to $10^{6}$ conidia/ml using sterile tap water. Before inoculation, Tween 20 was added to the inoculum to give $0.05 \%$ concentration.

A total of 35 pepper cultivars or accessions were evaluated for resistance to $C$. coccodes isolates: Korean cultivars Hanbyul, Kingkun, Dabogkun, Kwangbok, and Kumtap; Korean local collections KC178, KC190, KC195, KC205, KC206, $\mathrm{KC} 213, \mathrm{KC} 214, \mathrm{KC} 217, \mathrm{KC} 220$, and KC243 from the Department of Horticulture, Kyungbuk National University, Korea; U.S. local collections Cayenne Cajun 1A, Cayenne Cajun 2, Cayenne Cajun 2A, Peto Seed Cayenne, Capritto Cayenne, and Tabasco (Capsicum frutescens) from the Department of Plant Pathology and Crop Physiology, Louisiana State University; Indian accessions KC47 (PI 244670), KC49 (PI 249434), KC53 (PI 
257048), KC55 (PI 257052), KC56 (PI 257053), KC79 (PI 271322), KC118 (PI 322718), KC126 (PI 358812), KC127 (PI 369994), and KC130 (PI 369997) from the Department of Horticulture, Kyungbuk National University, Korea; and Thai local collections KC407 (F7 nun), KC408 (F6 Malasia), KC413 (Huai Sri Then), and KC 417 (Kantoorome) from the Department of
Horticulture, Kyungbuk National University, Korea.

Seeds of each pepper cultivar or accession were sown in plastic trays ( 55 by 35 by $15 \mathrm{~cm}$ ) containing a steam-sterilized soil mix of a commercial compost soil (peat moss:perlite:vermiculite, 5:3:2, $\mathrm{vol} / \mathrm{vol} / \mathrm{vol})$, sand, and loam soil (1:1:1, $\mathrm{vol} / \mathrm{vol} / \mathrm{vol}$ ). Ten seedlings at 2-leaf stage
First-branch stage

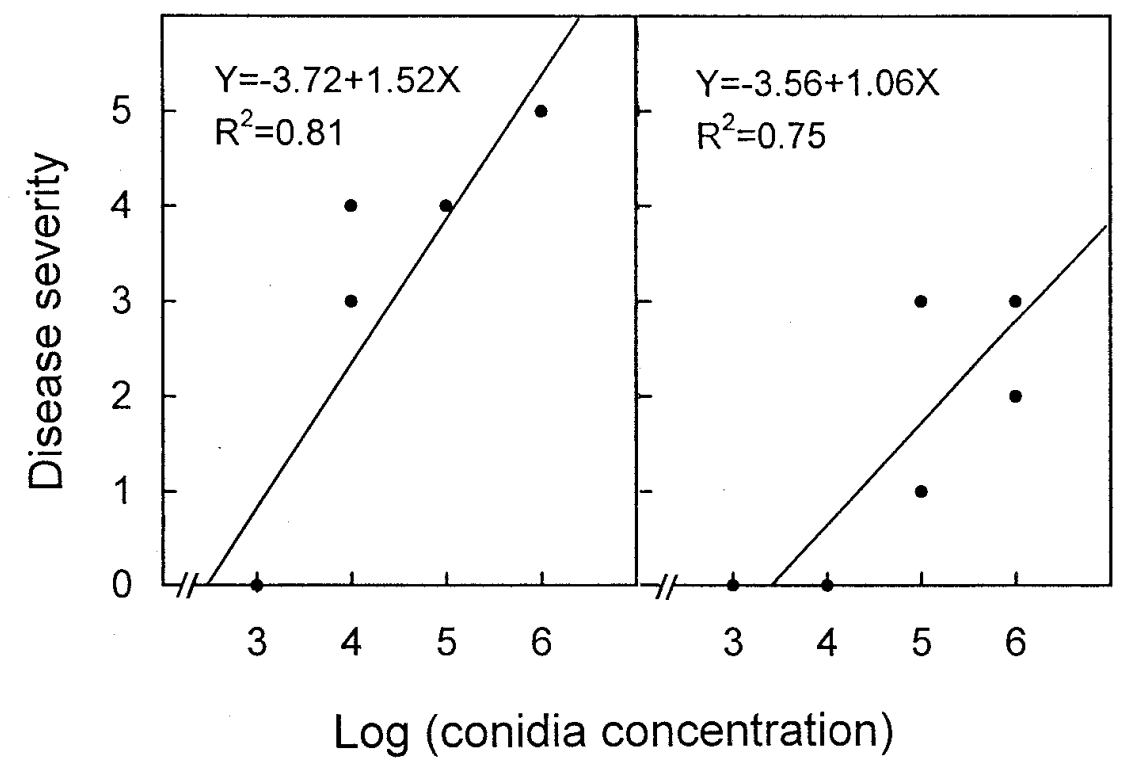

Fig. 1. Effect of inoculum concentration on disease development in pepper plants (cv. Hanbyul) inoculated with Colletotrichum coccodes isolate 32 by foliar spraying at the 2-leaf and first-branch stages. Disease severity rating based on a 0 to 5 scale, where $0=$ no visible symptoms and $5=$ plant dead.

\section{Two-leaf stage Eight-leaf stage}

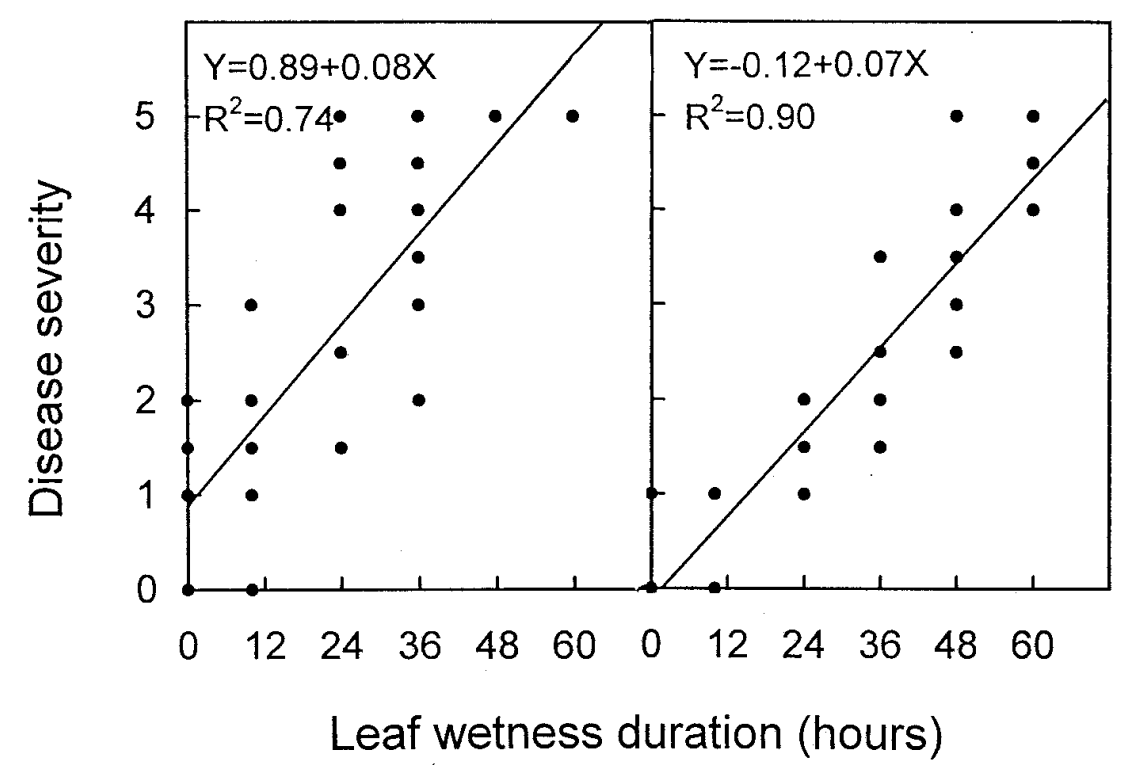

Fig. 2. Effect of wetness duration on disease development in pepper plants (cv. Hanbyul) inoculated with $2 \times 10^{5}$ conidia/ml of Colletotrichum coccodes isolate 32 by foliar spraying at the 2-leaf and 8leaf stages. Disease severity rating based on a 0 to 5 scale, where $0=$ no visible symptoms and $5=$ plant dead. were transplanted to plastic pots $(5$ by 15 by $10 \mathrm{~cm}$ ) containing the above-described soil mix. Pepper plants were grown in a growth room at $25 \pm 2{ }^{\circ} \mathrm{C}$ with $5,000 \mathrm{~lx}$ illumination for $16 \mathrm{~h} /$ day.

Inoculation procedures. Pepper plants at various growth stages were inoculated with a conidial suspension of $C$. coccodes by foliar-spray or soil-drench methods. For foliar-spray inoculation, a conidial suspension was sprayed to runoff over both sides of leaves using an atomizer. Inoculated plants were placed in a moist chamber at $28^{\circ} \mathrm{C}$ for $36 \mathrm{~h}$ and then returned to the growth room for disease evaluation. For soil-drench inoculation, $15 \mathrm{ml}$ of a suspension of conidia $\left(10^{6}\right.$ conidia $\left./ \mathrm{ml}\right)$ was uniformly poured over the soil surface in each pot. Immediately after soil-drenching, pots were placed in a large plastic tray and maintained in a growth room for disease evaluation.

To evaluate the effect of wetness duration on $C$. coccodes infection, pepper plants at the 2- and 8-leaf stages were sprayed with a conidial suspension of $C$. coccodes isolate $32\left(2 \times 10^{5}\right.$ conidia/ml $)$ and incubated in a moist chamber in a growth room at $28^{\circ} \mathrm{C}$ for $0,10,24,36,48$, and $60 \mathrm{~h}$. After incubation in the moist chamber, the plastic pots, each containing 10 inoculated pepper plants, were again placed in a growth room for disease evaluation.

Disease evaluation and data analysis. Disease development of pepper plants was recorded daily after inoculation of $C$. coccodes. To evaluate infection of $C$. coccodes on the inoculated plants, disease severity was rated based on a 0 to 5 scale, where $0=$ no visible symptoms; $1=$ small circular or irregular, gray-brown spots on leaves, and the plants slightly wilted; $2=$ some leaves defoliated with circular or irregular gray-brown lesions with dark brown edge on leaves, damping-off in seedlings, and 30 to $50 \%$ of the plant wilted; 3 = leaves defoliated with large irregular lesions and 50 to $70 \%$ of the plant wilted; 4 = leaves defoliated or desiccated, and 70 to $90 \%$ of entire plant wilted; and 5 $=$ plant dead. The number of lesions produced on leaves of pepper plants also were recorded at day 8 after inoculation. Disease severity ratings were used to calculate areas under disease progress curves (AUDPCs) using the formula:

$$
\text { AUDPC }=\sum_{i=1}^{n}\left(X_{i+1}+X_{i}\right)\left(t_{i+1}-t_{i}\right) / 2
$$

where $X_{\mathrm{i}}=$ disease severity at the $i$ th observation, $t_{\mathrm{i}}=$ time (days) at the $i$ th observation, and $n=$ total number of observations.

All data are the mean of disease ratings of 10 plants inoculated with $C$. coccodes. All experiments were repeated at least twice with similar results. Data represented are from one experiment. AUDPCs from one experiment were analyzed statistically 
by the analysis of variance procedures. Linear regression analyses were used to evaluate relationships between leaf wetness duration and inoculum density for disease development. The SAS computer program (SAS Institute Inc., Cary, NC) was used for all regression analyses.

\section{RESULTS}

Effect of inoculum density on disease development. Disease severity of Hanbyul pepper plants increased as inoculum density increased from $10^{3}$ to $10^{6}$ conidia $/ \mathrm{ml}$ (Fig. 1). A linear relationship was found between inoculum density and disease severity on pepper plants at the 2-leaf and first-branch stages. Conidia concentrations used for the inoculation explained 81 and $75 \%$ of the variation in disease severity $\left(r^{2}\right.$ $=0.81$ or 0.71 ) at the 2-leaf and firstbranch stages, respectively. Few symptoms were induced on pepper plants at the 2-leaf stage inoculated with $10^{3}$ conidia/ml and first-branch stage inoculated at $10^{3}$ and $10^{4}$ conidia/ml. Disease severity was intermediate (severity ratings of 2 to 3 ) at $10^{4}$ to $10^{5}$ conidia/ml. At $10^{6}$ conidia/ml, all juvenile plants at 2-leaf stage were killed (severity rating of 5) within 5 to 7 days after inoculation. At the first-branch stage, resistance to $C$. coccodes became more evident. After incubation for 4 days, foliar lesions coalesced on pepper leaves at the 2leaf stage, while foliar lesions were only light brown or gray flecks on plants at first-branch stage inoculated with $10^{5}$ and $10^{6}$ conidia $/ \mathrm{ml}$.

Effect of wetness duration on disease development. Disease severity increased in pepper plants (cv. Hanbyul) as the wetness duration increased (Fig. 2). A linear relationship was observed between leaf wetness duration and disease severity on pepper plants at the 2- and 8-leaf stages. Disease did not develop on pepper leaves that were not kept wet after inoculation. After exposure to continuous wetness for 48 or $60 \mathrm{~h}$, juvenile plants at 2-leaf stage were killed (severity rating of 5) 4 days after inoculation. At all wetness durations, disease developed slowly on pepper plants at the 8leaf stage compared with the 2-leaf stage.

Effect of plant age and inoculation method. In general, as pepper plants grew older, they became more resistant to $C$. coccodes (Fig. 3). At the 2-leaf stage, there were no differences between the foliar spray and soil-drench inoculations in disease severity. All the juvenile plants at the 2-leaf stage were killed by $C$. coccodes infection. Mean disease severity was less than 1 for plants inoculated by soil drench at the 4-leaf stage. At the 8-leaf and firstbranch stages, soil-drench inoculation did not cause disease. Foliar inoculation, however, produced small, circular, light-gray lesions on the pepper leaves at the 8-leaf and the first-branch stages.

Cultivar resistance to $C$. coccodes isolates. Prior to evaluating the resistance of pepper cultivars or accessions to $C$. coccodes, levels of virulence of some $C$. coccodes isolates 7-48, 2-25, and 32 were examined in pepper plants (cv. Hanbyul) at the 2- and 6-leaf stages. Isolate 2-25 was more virulent than isolate 32 on pepper plants. Isolate 7-48 was not pathogenic to the pepper plants (data not shown) and was not included in further evaluations.

When inoculated by foliar spray at the 2leaf stages with each isolate (2-25 and 32), all the cultivars or accessions tested had small, circular, light-gray lesions on the leaves, external discoloration on the stem, a sudden wilt of the entire plant, leaf defoliation, or damping-off (data not shown). No hypersensitive symptoms were observed in any of the cultivars tested. In general, all cultivars or accessions at the 4leaf stage were susceptible to the two iso-

\section{o-o Foliar spray}

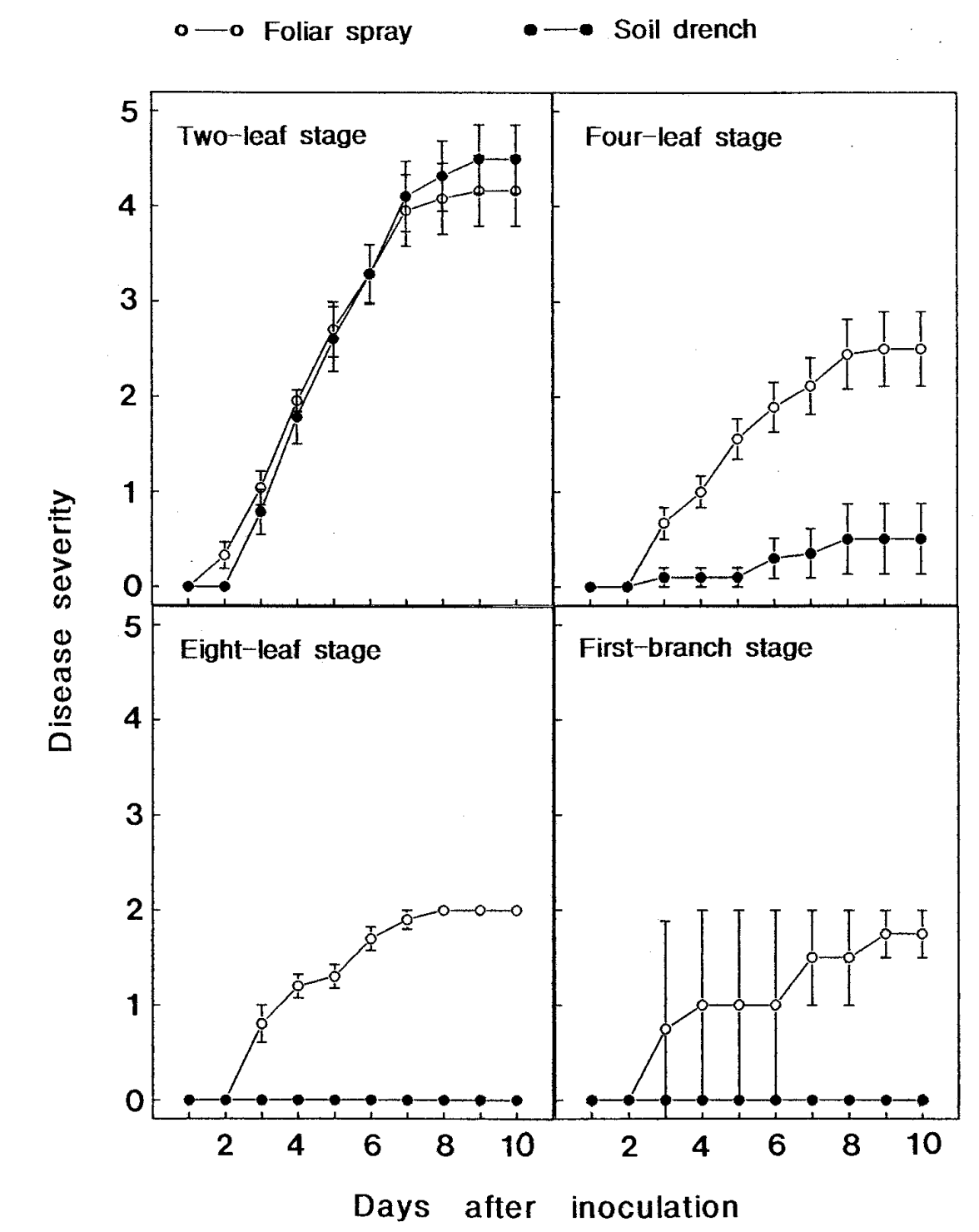

Fig. 3. Effect of plant age and inoculation method on disease development in pepper plants (cv. Hanbyul) inoculated with Colletotrichum coccodes isolate 32 . Disease severity rating based on a 0 to 5 scale, where $0=$ no visible symptoms and $5=$ plant dead. Bars represent standard error of the mean. evaluate the relative resistance of the 35 pepper cultivars or accessions to the two isolates of $C$. coccodes (Table 1). Korean cultivars were quantitatively more resistant to isolate 32 than isolate $2-25$. In contrast, the U.S. local peppers were more resistant to isolate 2-25. In particular, the U.S. local pepper Tabasco (Capsicum frutescens) showed a high level of resistance to both isolates, compared with the other pepper cultivars or accessions tested. The other Indian, Korean local, and Thai collection peppers showed similar disease severity to

The analysis of variance of the AUDPCs in this experiment (Table 2) showed significant differences among cultivars and for the cultivar $\times$ isolate interaction, but not between isolates. lates (2-25 and 32). AUDPCs were used to the two tested isolates. 
The Korean cultivars Hanbyul and Kwangbok, which were susceptible and resistant to $C$. coccodes, respectively, were reevaluated by foliar-spray inoculation with the two isolates, 2-25 and 32, on pepper plants at different growth stages using foliar spray technique (Table 3). More lesions were produced on the leaves of the cultivar Hanbyul than the cultivar Kwangbok, irrespective of plant growth stage and $C$. coccodes isolate. The total number of lesions produced per square centimeter leaf decreased as the pepper plants matured.

\section{DISCUSSION}

Inoculum density of $C$. coccodes affected anthracnose development in pepper seedlings at the two developmental stages. With a low level of inoculum density $\left(10^{3}\right.$ conidia/ml), a few symptoms appeared on pepper seedlings at 2-leaf stage 4 days after inoculation. Generally, as inoculum density increased, symptom development increased. With a high level of inoculum density $\left(10^{6}\right.$ conidia $\left./ \mathrm{ml}\right)$, initial lesions appeared 3 days after inoculation, suggesting that higher inoculum densities may contribute to rapid development of anthracnose. These results agree with the observations of Dillard (9), in which anthracnose severity on tomato fruit increased as inoculum density increased from $10^{1}$ to $10^{6}$ conidia $/ \mathrm{ml}$. At the firstbranch stage, inoculum above $10^{5}$ con$\mathrm{idia} / \mathrm{ml}$ was required for disease development. These results imply that mature pepper plants can effectively avoid $C$. coccodes infection compared with pepper seedlings at the 2-leaf stage. Primary inoculum density of $C$. coccodes seems to be important for producing typical anthracnose lesions on pepper plants. In an earlier study, it was demonstrated that primary inoculum density of $C$. coccodes was related to the induction and development of anthracnose of tomato fruit (9).

Available moisture was critical for infection of pepper leaves by $C$. coccodes. At the 2-leaf stage, pepper plants receiving 48 and $60 \mathrm{~h}$ of leaf wetness were severely blighted by $C$. coccodes infection. At least 24 to $36 \mathrm{~h}$ of leaf wetness seemed to be necessary for inducing naturally occurring symptoms of anthracnose under the greenhouse conditions. Moisture is known to be a very important factor for both the survival of $C$. coccodes in soil (11) and the infection in tomato fruits and potato foliage $(9,15)$. The significance of moisture in C. coccodes infection on host plants such as pepper, tomato, and potato is supported by the previous findings of Pantidou and Schroeder (20), who showed that $C$. phomoides (a synonym of C. coccodes) could grow and sporulate abundantly on tomato leaves, depending upon the length of the postinfection humidity period. Microclimates of high temperature and high humidity in seedbeds of polyethylene film-
Table 1. Area under disease progress curves (AUDPCs) a 35 pepper cultivars or accessions inoculated by foliar spray at the 4-leaf stage with two Colletotrichum coccodes isolates 2-25 and 32

\begin{tabular}{|c|c|c|}
\hline \multirow[b]{2}{*}{ Origin, cultivar or accession } & \multicolumn{2}{|c|}{ AUDPC by two isolates (mean \pm SE) } \\
\hline & Isolate 2-25 & Isolate 32 \\
\hline \multicolumn{3}{|l|}{ Korean cultivar } \\
\hline Hanbyul & $25 \pm 2.0$ & $16 \pm 4.9$ \\
\hline Kingkun & $26 \pm 1.2$ & $13 \pm 1.0$ \\
\hline Dabogkun & $18 \pm 4.4$ & $17 \pm 8.1$ \\
\hline Kwangbok & $11 \pm 2.4$ & $11 \pm 1.5$ \\
\hline Kumtap & $19 \pm 2.4$ & $15 \pm 5.5$ \\
\hline Average & 20 & 14 \\
\hline \multicolumn{3}{|l|}{ Korean local collection } \\
\hline KC178 & $17 \pm 5.5$ & $22 \pm 10.8$ \\
\hline KC190 & $17 \pm 3.9$ & $13 \pm 3.0$ \\
\hline КC195 & $29 \pm 1.7$ & $36 \pm 1.1$ \\
\hline KC205 & $18 \pm 5.3$ & $17 \pm 6.3$ \\
\hline KC206 & $15 \pm 4.4$ & $22 \pm 6.6$ \\
\hline KC213 & $19 \pm 3.4$ & $21 \pm 7.1$ \\
\hline KC214 & $21 \pm 1.1$ & $13 \pm 2.5$ \\
\hline KC217 & $20 \pm 2.9$ & $23 \pm 6.5$ \\
\hline KC220 & $21 \pm 2.1$ & $16 \pm 4.3$ \\
\hline KC243 & $17 \pm 1.6$ & $22 \pm 6.8$ \\
\hline Average & 19 & 21 \\
\hline \multicolumn{3}{|l|}{ U.S. local collection } \\
\hline Cayenne Cajun 1A & $21 \pm 2.5$ & $32 \pm 6.2$ \\
\hline Cayenne Cajun 2 & $17 \pm 2.1$ & $28 \pm 3.0$ \\
\hline Cayenne Cajun 2A & $21 \pm 5.4$ & $26 \pm 4.6$ \\
\hline Peto Seed Cayenne & $25 \pm 1.9$ & $24 \pm 8.2$ \\
\hline Capritto Cayenne & $20 \pm 3.4$ & $22 \pm 8.5$ \\
\hline Tabasco(Capsicum frutescens) & $13 \pm 4.5$ & $10 \pm 0.8$ \\
\hline Average & 20 & 24 \\
\hline \multicolumn{3}{|l|}{ Indian accessions } \\
\hline KC47 (PI244670) & $18 \pm 4.7$ & $15 \pm 2.6$ \\
\hline KC49 (PI249434) & $17 \pm 1.5$ & $21 \pm 5.1$ \\
\hline KC53 (PI257048) & $24 \pm 4.0$ & $27 \pm 5.6$ \\
\hline KC55 (PI257052) & $24 \pm 1.9$ & $16 \pm 5.4$ \\
\hline KC56 (PI257053) & $19 \pm 1.3$ & $20 \pm 4.7$ \\
\hline KC79 (PI271322) & $16 \pm 2.8$ & $19 \pm 5.5$ \\
\hline KC118 (PI322718) & $21 \pm 1.5$ & $21 \pm 5.8$ \\
\hline KC126 (PI3588412) & $17 \pm 4.4$ & $16 \pm 3.8$ \\
\hline KC127 (PI369994) & $27 \pm 1.4$ & $16 \pm 2.4$ \\
\hline KC130 (PI369997) & $13 \pm 4.6$ & $15 \pm 1.8$ \\
\hline Average & 20 & 19 \\
\hline \multicolumn{3}{|l|}{ Thai collection } \\
\hline KC407 & $16 \pm 3.1$ & $15 \pm 5.8$ \\
\hline KC408 & $15 \pm 3.4$ & $17 \pm 5.0$ \\
\hline KC413 & $27 \pm 2.9$ & $21 \pm 8.0$ \\
\hline KC417 & $16 \pm 5.6$ & $22 \pm 7.5$ \\
\hline Average & 19 & 19 \\
\hline
\end{tabular}

${ }^{a}$ AUDPCs were calculated using a disease severity rating based on a 0 to 5 scale, where $0=$ no visible symptoms and $5=$ plant dead.

Table 2. Analysis of variance of the areas under disease progress curves of 35 cultivars or accessions inoculated with two isolates of Colletotrichum coccodes

\begin{tabular}{lcccc}
\hline Source of variation & df & Mean square & $\boldsymbol{F}$ value & $\boldsymbol{P}$ \\
\hline Cultivar or accession & 34 & 232.8 & 9.8 & $<0.01$ \\
Isolate & 1 & 9.8 & 0.4 & $>0.01$ \\
Cultivar or accession $\times$ isolate & 34 & 151.1 & 6.3 & $<0.01$ \\
\hline
\end{tabular}

Table 3. Comparison of lesion development (mean number lesions $/ \mathrm{cm}^{2}$ leaf) on the leaves of pepper cultivars Hanbyul (susceptible) and Kwangbok (resistant) foliar-spray inoculated with Colletotrichum coccodes isolates 2-25 and 32 at different growth stages

\begin{tabular}{lccccc}
\hline & \multicolumn{2}{c}{ Isolate 2-25 } & & \multicolumn{2}{c}{ Isolate 32 } \\
\cline { 2 - 3 } \cline { 5 - 6 } Plant growth stage & Hanbyul & Kwangbok & & Hanbyul & Kwangbok \\
\hline 6-leaf & $4.1 \pm 0.7^{\mathrm{a}}$ & $3.2 \pm 0.7$ & & $1.5 \pm 0.6$ & $1.1 \pm 0.5$ \\
8-leaf & $2.4 \pm 0.4$ & $1.7 \pm 1.2$ & & $0.7 \pm 0.6$ & $0.3 \pm 0.3$ \\
First-branch & $1.9 \pm 0.7$ & $0.8 \pm 0.3$ & & $0.2 \pm 0.1$ & $0.1 \pm 0.1$ \\
\hline
\end{tabular}

a Mean numbers evaluated 8 days after inoculation. Each value represents a mean \pm standard error of seven plants. 
houses may serve as favorable environmental factors for anthracnose development in pepper seedlings (21).

Inoculation method influences infection and lesion development of $C$. coccodes on pepper leaves. Foliar application of a conidial suspension produced anthracnose lesions on pepper leaves at all development stages of the plants. Root infection of $C$. coccodes by soil drench caused dampingoff of pepper seedlings only at 2-leaf stage. Thus, a large number of pepper seedlings may be severely damaged by $C$. coccodes infection of roots growing in seedbeds (21). In contrast, anthracnose caused by $C$. coccodes does not result in the severe epidemics in mature leaves and fruits of pepper, possibly because of its weak parasitism $(6,12)$ combined with a low competitive saprophytic ability (14).

All pepper cultivars became increasingly resistant to $C$. coccodes as plants aged. Expression of the age-related resistance to anthracnose was more apparent in pepper plants at late growth stages inoculated by the soil-drench method. These facts suggest that the soil-borne fungus $C$. coccodes can infect only pepper seedlings at 1- or 2leaf stages through root tissues. In an earlier study, Kim et al. (17) demonstrated the expression of age-related resistance in pepper plants infected with the soil-borne fungus Phytophthora capsici.

The foliar-spray inoculation method was effective at evaluating pepper cultivars or accessions for resistance to $C$. coccodes at the 4-leaf stage of plants. Soil-drench inoculation, however, may not be appropriate for evaluating cultivar resistance on old pepper plants, because symptoms were not induced on pepper plants older than 4-leaf stage. The responses of 35 cultivars or accessions to two isolates of $C$. coccodes were evaluated by foliar-spray inoculations done under controlled environmental conditions. Hypersensitive reactions were not observed in any of the pepper cultivars of diverse genetic origins inoculated with $C$. coccodes, indicating that the difference between the susceptible and resistant responses to $C$. coccodes were more quantitative than qualitative. Significant differences in susceptibility to $C$. coccodes isolates were not observed among the Korean, U.S. local, Indian, and Thai cultivars or accessions tested, irrespective of genetic or country origin of cultivars. The Korean cultivar, Kwangbok, and the U.S. local pepper, Tabasco (Capsicum frutescens), showed a high level of resistance to the $C$. coccodes isolates tested, suggesting a possible existence of resistance sources in pepper. Although inheritance of resistance to tomato anthracnose is known to be controlled by several genes $(2,3,18)$, there is little information on sources and inheritance of resistance to $C$. coccodes in pepper. Planting cultivars such as Kwangbok, which exhibit resistance to anthracnose, may be effective in reducing outbreaks of damping-off caused by $C$. coccodes in pepper seedling plants in seedbeds.

\section{ACKNOWLEDGMENTS}

We thank B. S. Kim of Kyungbuk National University, and C. H. Kim of National Agricultural Sciences and Technology Institute, Korea, for providing pepper seeds of different origins and $C$. coccodes isolates, respectively.

\section{LITERATURE CITED}

1. Barksdale, T. H. 1967. Light-induced in vitro sporulation of Colletotrichum coccodes causing tomato anthracnose. Phytopathology 57:1173-1175.

2. Barksdale, T. H. 1971. Inheritance of tomato anthracnose resistance. Plant Dis. Rep. 55:253-256.

3. Barksdale, T. H. 1972. Anthracnose resistance in $\mathrm{F}_{2}$ populations derived from ten tomato introductions. Plant Dis. Rep. 56:321-323.

4. Barksdale, T. H., and Koch, E. J. 1969. Methods of testing tomatoes for anthracnose resistance. Phytopathology 59:1373-1376.

5. Byrne, J. M., Hausbeck, M. K., and Hammerschmidt, R. 1997. Conidial germination and appressorium formation of $\mathrm{Col}$ letotrichum coccodes on tomato foliage. Plant Dis. 81:715-718

6. Chester, C. G. C., and Hornby, D. 1965. Studies on Colletotrichum coccodes. II. Alternative host tests and tomato fruit inoculations using a typical tomato root isolate. Trans. Br. Mycol. Soc. 48:583-594.

7. Dickson, B. T. 1926. The "black dot" disease of potato. Phytopathology 16:23-40.

8. Dillard, H. R. 1988. Influence of temperature, $\mathrm{pH}$, osmotic potential, and fungicide sensitivity on germination of conidia and growth from sclerotia of Colletotrichum coccodes in vitro. Phytopathology 78:1357-1361.

9. Dillard, H. R. 1989. Effect of temperature, wetness duration, and inoculum density on infection and lesion development of Colletotrichum coccodes on tomato fruit. Phytopathology 79:1063-1066.

10. Dillard, H. R., Johnston, S. A., Cobb, A. C., and Hamilton, C. H. 1997. An assessment of fungicide benefits for the control of fungal diseases of processing tomatoes in New York and New Jersey. Plant Dis. 81:677-681.

11. Farley, J. D. 1976. Survival of Colletotrichum coccodes in soil. Phytopathology 66:640-641.

12. Gemeinhardt, H. 1957. Untersuchungen über den Saprophytisums des Collotrichum atramentarium (B. et Br.) Taub. und die Lebensdauer der Sklerotien (Acervuli) des Pilzes. Phytopathol. Z. 29:151-176.

13. Higgins, B. B. 1926. Anthracnose of pepper (Capsicum annuum L.). Phytopathology 16:332-347.

14. Hornby, D. 1968. Studies on Colletotrichum coccodes. III. Some properties of the fungus in soil and in tomato roots. Trans. Br. Mycol. Soc. 51:541-553.

15. Johnson, D. A., and Miliczky, E. R. 1993. Effects of wounding and wetting duration on infection of potato foliage by Colletotrichum coccodes. Plant Dis.77:13-17.

16. Kendrick, J. B., Jr., and Walker, J. C. 1948 Anthracnose of tomato. Phytopathology 38:247-260.

17. Kim, Y. J., Hwang, B. K., and Park, K. W 1989. Expression of age-related resistance in pepper plants infected with Phytophthora capsici. Plant Dis. 73:745-747.

18. Miller, A. N., Ng, T. J., and Barksdale, T. H. 1984. Comparison of inheritance of resistance to anthracnose caused by two Colletotrichum spp. Plant Dis. 68:875-877.

19. Oh, I. S., In, M. S., Woo, I. S., Lee, S. K., and Yu, S. H. 1988. Anthracnose of pepper seedling caused by Colletotrichum coccodes (Wallr.) Hughes. Kor. J. Mycol. 16:151-156.

20. Pantidou, M. E., and Schroeder, W. T. 1955. Foliage as a source of secondary inoculum for tomato anthracnose. Phytopathology. 45:338345.

21. Park, K. S., and Kim, C. H. 1992. Identification, distribution, and etiological characteristics of anthracnose fungi of red pepper in Korea. Kor. J. Plant Pathol. 8:61-69.

22. Raid, R. N., and Pennypacker, S. P. 1987. Weeds as hosts for Colletotrichum coccodes. Plant Dis. 71:643-646.

23. Sanogo, S., Pennypacker, S. P., Stevenson, R. E., and MacNab, A. A. 1997. Weather variables associated with infection of tomato fruit by Colletotrichum coccodes. Plant Dis. 81:753-756.

24. Yu, S. H., Park, J. S., Oh, I. S., Wu, I. S., and Mathur, S. B. 1987. Colletotrichum coccodes found in seeds of Capsicum annuum and pathogenicity to Solanaceae plants. Kor. J Mycol. 15:183-186. 